\title{
Data Driven Through Machine Learning on Electricity Production by Anode Respiring Bacteria Using the Microbial Fuel Cells
}

\author{
Mustafa Kamal Pasha ${ }^{\text {a }}$, Khurram Munawar ${ }^{\mathrm{a}}$ \\ aDepartment of Environment, Society and Design, Lincoln University - New Zealand" \\ Email: kpasha2003@gmail.com
}

Received: 08 November 2020; Accepted: 20 January 2021; Published: 08 June 2021

\begin{abstract}
Microbial Fuel Cell (MFC) is a bio-electrochemical device that generates electric current by using bacteria. MFCs are currently a topic of intense research and interest due to their ability to produce renewable energy along with added benefits such as wastewater treatment. Although the theoretical concepts and applicability of MFCs are great, their application, thus far has been limited due to the limits of power production. Current research aims to improve the efficiency as well as the upper limit of power production by MFCs. In parallel to current research, this study is designed with a similar aim to do a comprehensive data analysis on the topic of MFCs by using techniques of Artificial Intelligence. Therefore, we started this study by obtaining the relevant data through an extensive literature retrieval for developing Artificial Neural Network model. The data from the output layer was viewed by using VOSviewer software and was further subjected to analysis. The data collected through machine learning provided an insight about the optimal conditions of MFCs which would allow for maximum current production. It discusses two existing types of MFCs; namely mediator type and mediator free type of MFC. Anode respiring bacteria (ARB), also known as exoelectrogenes can be used as the mediator to transfer electrons by utilizing the substrate present at the anode. Our results suggest that different combinations of bacterium and biofilms can produce more electric current with improved stability. This study will provide an insight to improve the working capacity of MFCs. It is likely that MFCs will one day be used as a stand-alone power production method by optimizing the current production capacity. Moreover, these advancements will have a significant by utilizing MFCs for making chips and biosensors, and treating wastewater.
\end{abstract}

Index Terms: MFCs, ARB, Machine Learning, ANN

\section{Introduction}

A number of micro-organisms belong to the aerobic families of microbes. These microbes can convert biochemical energy stored in the ATP molecules, which implies that by using oxygen, these microbes can utilize the chemical energy stored in the ATP molecules and convert it into electrical energy [1]. This conversion is done by the transfer of electrons from one terminal (anode) to another terminal (cathode) due to microbial activity at the anode. The recent literature shows that the anode respiring bacteria transfer electrons present in the organic or inorganic substrates. Selection of suitable anode respiring bacteria for setting up microbial fuel cells depend on anode potential as maintenance of microbial colony and its growth depends on energy available at anode [2]. The electron acceptors can be solid substances such as oxides, nitrates and sulphates [3]. Meanwhile, some other microbes may respire through different solid electron acceptors to gain energy [4]. Data derived through machine learning can help us to find out a number of ways in which the electron transfer can occur within a microbial cell [1]. These methods include the use of heterolytic compounds or the use of a macrophage containing hemosiderin, in both of these mechanisms, the solubility of solid electron acceptors is enhanced before incorporating in the cell [4].

In the improved efficiency of microbial fuel cells, the kinetics of Anode Respiratory Bacteria play a key role [5]. Therefore, while setting up a microbial fuel cell, it is important to select a suitable electron donor compound. For example, acetate is a very effective electron donor substrate. The kinetics of acetate are a bit higher than other compounds and this compound cannot be fermented [6].The low values of $\mathrm{K}$ suggest that the Anode Respiring Bacteria that can deposit onto the anode will be oligotropic in nature and the higher values of $\mathrm{K}$ suggests the opposite i-e; nonoligotropic bacteria will deposit on the anode. The high $\mathrm{q}_{\max }$ value in comparison with low $\mathrm{K}$ values predicts that the anode respiring microbe can utilize substrate even at low concentration of substrate. This condition is said to be ideal for the ARB and microbial fuel cells as it allows microbial growth that is linked with efficiency of MFC even when substrate is depleting [7]. 
Data collected from the study of (Heilmann \& Logan, 2006) explained that, as a general rule, the microorganisms consume sugar in aerobic conditions and produce carbon dioxide and water [8]. Anaerobic MFCs, however, utilize the power of microorganisms in anaerobic conditions. In the anaerobic conditions, microorganisms produce carbon dioxide, protons, and electrons. A study by (Logan et al., 2006) proves that inorganic mediators such as natural red, methylene blue, or thionine are used by MFCs to tap into the electron transport chain of microorganisms and, in anaerobic conditions, it channel the generated electrons[9]. The mediator crosses the bacterial membrane of the microorganisms and liberates electrons from the ETC which would normally be taken up by oxygen due to its increased electro negativity. The reduced mediator then exits the cell and transfers it to an electrode which becomes the anode. This oxidizes the mediator returning it to its original state, ready to carry out its function again [9]. In a study, a comparison of electricity production by aerobic and anaerobic MFCs was done. Results suggested that aerobic MFCs have a greater potential of electricity production compared to anaerobic MFCs as duration of gas retention was considerably low in anaerobic MFCs which served as a limiting factor [10].

Microbial fuel cells are classified as either mediator type or mediator-less type of MFCs based on transfer of electrons to anode from bacteria. In the former type of MFC i.e mediator type MFCs, bacteria require agents that facilitate the electron transfer between electrode and the microorganism because these bacteria lack such surface proteins which can assist in this transfer. However, in the latter type of MFC i.e mediator-less MFCs no mediator is required by microbial colonies to transfer the electrons to the electrode. Therefore, they are mostly dependent on metal reducing bacteria and are less toxic and cost effective [11]. Numerous benefits are associated with both mediator type or mediator-less MFCs along with some associated loopholes as well.

All this data suggests that MFCs are constantly evaluated for improving their working capacity. It includes substances to be used as electrodes, microbial colonies, mediators, electrode potential, energy, current generation and many more factors. Therefore, in order to improve the electricity generation of MFCs by using anode respiring bacteria, it is important to comprehensively study MFCs in terms of its assembly, its making, electrode potentials, bacterial colonies and the limiting factors which limit the electricity production of MFCs. As a clear difference in outcomes of mediator and mediator less MFCs is present, therefore, in order to improvise the MFCs, current knowledge should be known and the research gaps must be identified. Owing to the increased use of computers and internet sources, machine learning utilizes the idea of vast volumes of data being produced every day in various fields [12, 13]. Therefore, approach of machine learning will be utilized in this study to answer the use of MFCs for the benefit of the general public; however, with the continued research in this field, it is a future goal to use the MFCs in lower power systems such as water treatment facilities $[14,15]$.

This study is conducted with the aim to utilize the advancements of AI by applying the principles of Artificial Neural Networks to gain an insight of existing types of MFCs in order to improvise them. Artificial Neural Networks work on similar principles as that of a human brain in which information is stored through the input layer that is processed by hidden layer and ultimately results are displayed by output layer and are further subjected to analysis. Previously, it was the areas of industry and education that were seen to be wining from the new technologies. But, the recent years have seen an increase in the need of integrating the modern age equipment in the field of health and biological sciences [16]. Other than computer, the devices like antennas and wireless devices can also be used for the collection of data. As the data collected through these devices would have large benefits, such as wearable antennas are now being used in personal wellbeing, entertainment, military and biological sciences [17- 21]. Therefore, data was obtained from the authentic internet sources and was fed into the ANN model. The output of this ANN model was comprehensively evaluated and a detailed descriptive analysis of the available literature is given in this study. This study will provide a comprehensive analysis of Microbial Fuel Cells and a basis to modern research to improve the working capacity of MFCs so that they can be exploited in a sustained way to obtain electrical energy on a larger scale.

\section{Methodology}

The framework of this research is depicted through Fig.1. We started this study by formulating the research question and the keywords for this study were listed down. Based on these keywords, literature was retrieved and relevant data was obtained that was subjected to ANN modelling for efficient processing and data interpretation. Based on the results of ANN model, articles were collected for further data analysis 


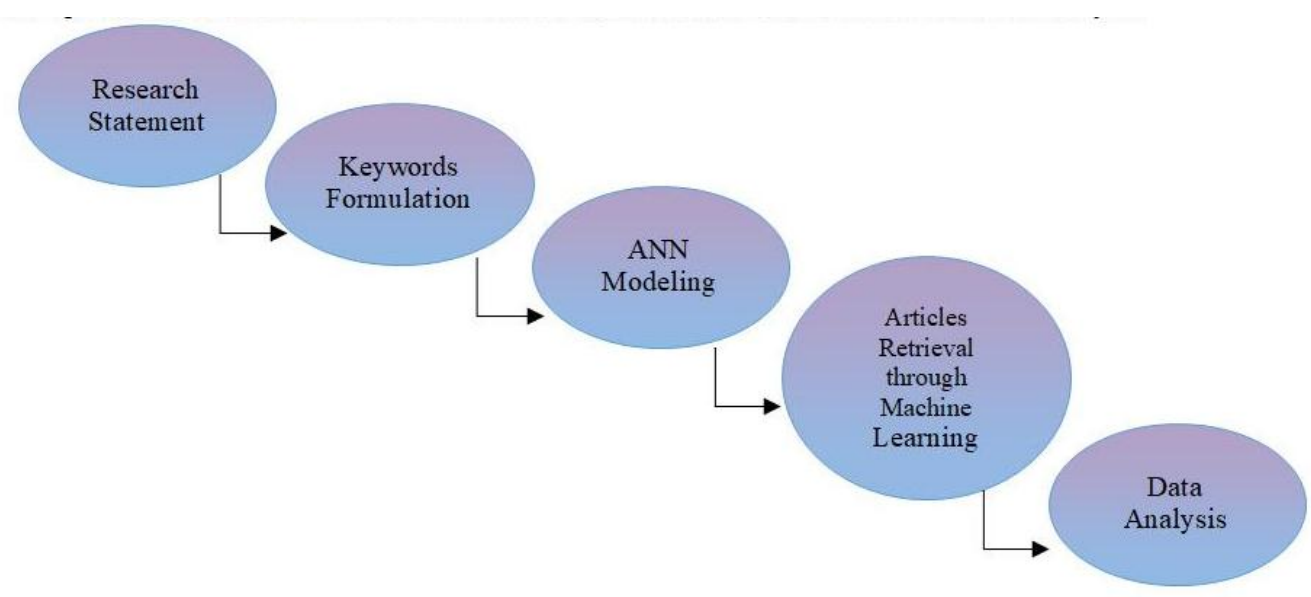

Fig. 1 Framework of Research

The AI methodology adopted for this research is shown in Fig. 2. As this study utilizes ANN approach for efficient evaluation of the data, therefore, input data on experimental design of MFCs was obtained from top-tier journals. Hidden layer processes the data and the output layer displays the processed data on possible methods for the generation of electricity by MFCs through AI.

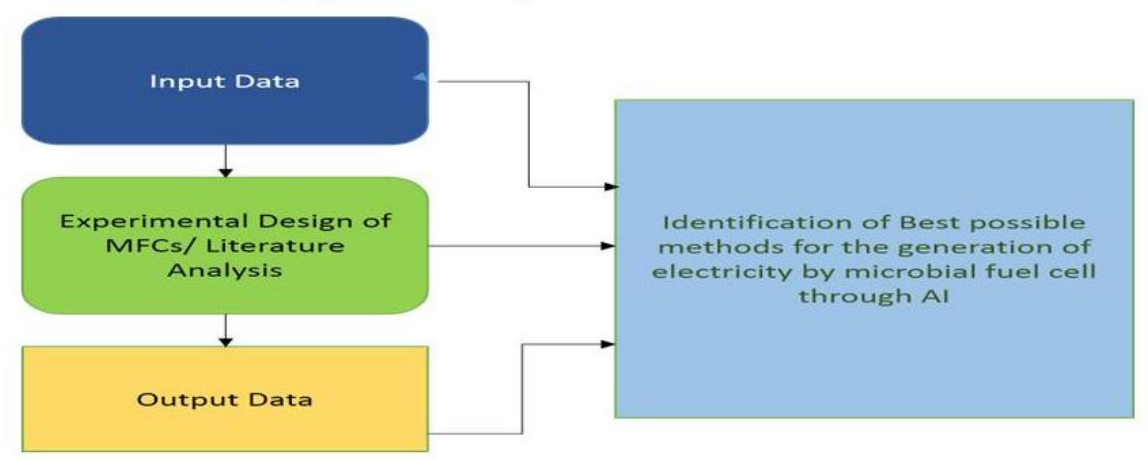

Fig. 2 AI based methodology adopted for identification of best method for the generation of electricity through MFC

\section{1 Keywords formulation and data retrieval}

Data was collected through an extensive literature retrieval from different research engines including Scopus, web of science, science direct etc., through a combination of keywords. High index papers published in top-tier journals were selected to carry out this research. After selection of the multiple sets of articles, different keyword queries were formulated and depending on the most researched keywords data was collected and compared. The keywords used for this research includes "Electricity Production through Bacteria", "Electricity Production through Anode Respiring Bacteria", and "Electricity Production through Microbial Fuel Cells". To make arrangements between articles obtained by using these keywords, ANN model was used which is explained below in detail.

\section{2 ANN model}

The Multilayer Artificial Neural Network uses three layers as shown in Fig. 3 as the input layer, hidden layer and an output layer. These layers collect the complex data on microbial fuel cells and processes them in the same way as a human brain would do. After this neurons links were made using feedback loops. The ultimate aim of these complex networks is to find the weight of the data. This ANN model provides the detailed data on the microbial fuel cells. Using this ANN approach all the data is collected and is subjected to interpretation in this research. 


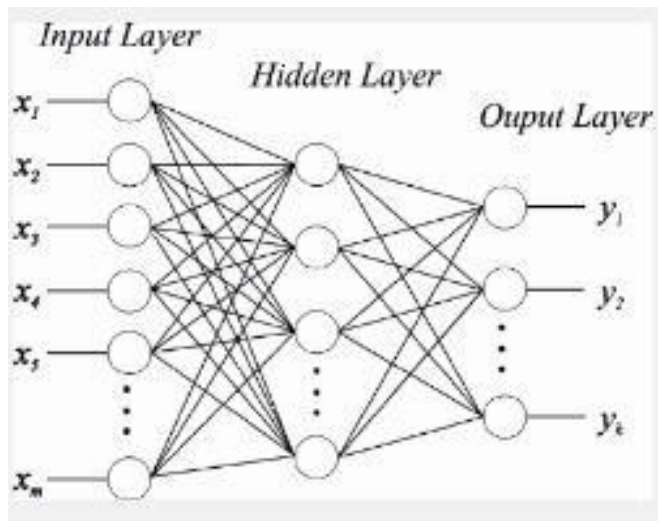

Fig. 3 ANN model for this research

\section{Results}

\subsection{Interpretation of ANN Model}

The data obtained through the output layer of ANN was viewed as the network given in Fig. 4 by using VOSviewer software. The nodes of this network represent the domains explored for MFCs while their size represents the weight of the data, or in other words the amount of work done under these domains. The lines between the nodes represent the interconnectedness of these research areas. The most repetitive keywords found in the articles includes microbial fuel cells, electron transfer, electron acceptor, microbial community, potential, energy, MFCs systems, wastewater treatment, and microbial energy etc. as shown in Fig. 4. This showed the data collected for this research revolved on electricity production through microbial fuel cell, which is the main exploratory area of this research.

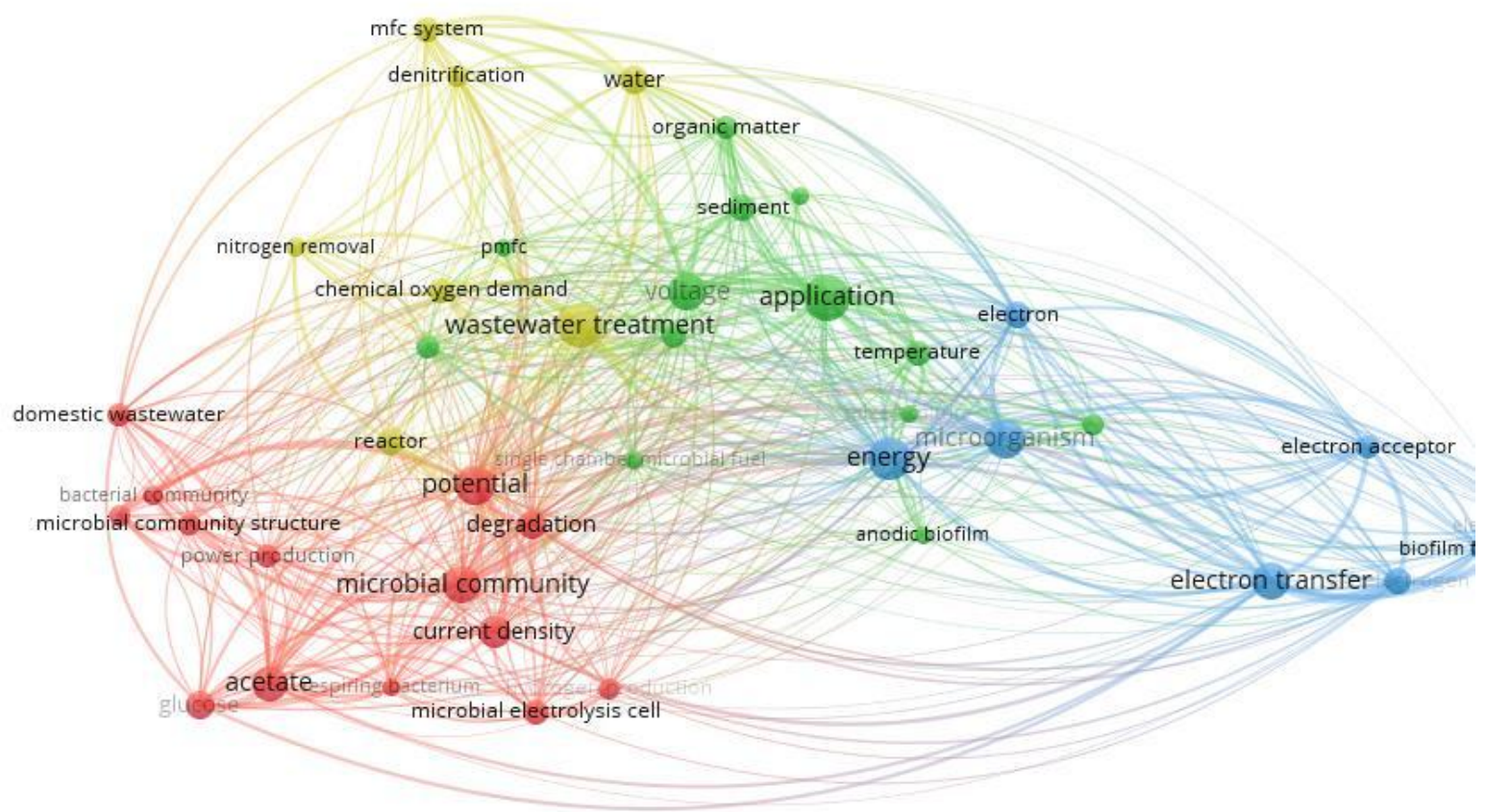

Fig. 4 Most repetitive keywords used in research articles related to electricity production through

\subsection{Descriptive analysis of data obtained on Microbial Fuel Cells via machine learning}

After the collection of data through machine learning, the best possible methods for electricity production through microbial fuel cells were evaluated and are discussed below in detail with the future suggestions and benefits of MFCs

\footnotetext{
3.2.1 Data derived through machine learning on identification of the Anode Respiring Bacteria and the process of electric current generation
} 
The production of electric current depends on the ability of an anode respiring bacteria to utilize particular substrate [6]. According to Pierra et al, anode potential should be used as a base quantity for the selection of anode respiring bacteria. Anode potential of ARB is also used to determine the amount of energy required for the maintenance and growth of the bacteria [22].

The best method found in the data for analysis of anode potential of anode respiring bacteria is to use biofilm microbial electrolysis cell that contains four graphite rods. All the four graphite rods must be at different potential. For this purpose the best substrate and the inoculums that should be used are acetate and waste-water sludge, respectively [2]. Studies by (Pierra et al., 2015;) showed that the anode at the lowest potential gave the fastest growth of biofilm than the higher potential[22].

The anode potential is also used to determine the properties of bacteria. This was explored in a study by setting up a reaction consisting of three reactors. Acetate was used in the reactor in which all the anodes were at their dignified potentials i.e. $0\left(R_{0}\right),-200\left(R_{200}\right),-400\left(R_{400}\right)$. On initial stages the anode potential had no effect on the three reactors used. After 31 days it was observed that the potential rod 200 was exhibiting highest value as compared to other two rod. The biomass activity of $\mathrm{R}_{400}$ was observed to be the highest [22].

The production of electric current by the anode respiring bacteria is basically transfer of electrons outside the membrane. As the movement of electrons toward the positive electrode defined as electric current similarly when an anode respiring microbe generates electrons, they are transferred outside the cell using the mechanism of Extracellular Electron Transport (EET) [23].

Study conducted by Yasri \& Nakhla, 2016), proved that if anode respiring bacteria are raised on anodes intoxicated with metals $\mathrm{CaS}$ and $\mathrm{FeS}$, it indicates that the bacterial growth and the ability of bacterium to transport electrons outside the membrane by EET is enhanced. It is also observed that the anode doped with CaS was more effective in increment of capabilities of microbes. The value of current density of $\mathrm{CaS}$ was calculated $22.0 \mathrm{Am}^{-2}$ and the density of FeS was calculated to be $8.4 \mathrm{Am}^{-2}$. as from the above calculations it is evident that the graphite rod doped with CaS is considered to be the most suitable material for the bio-electro-chemical systems BES. [24].

According to the, (Yasri \& Nakhla, 2016) the processes that must be used to indicate the electrochemical pathways are simple cycle voltameter and derivative cyclic voltameter [23]. The low value of electrocution activity of a microbe plays the main role for the mediators' accumulation on the anode. A number of different bacterial species, found in literature, which can be classified as ARBs as they can effectively transfer electrons and generate electricity include the Geobacter, Clostridium, and Shewanella species [24]. The list of these species is constantly being updated through research. Thermincola, a Gram-positive bacteria which has been reported to be a thermophile is known to generate energy by means of following the anodic respiration pattern. Through experimentation, it was observed that the cultures of the specie grew well at density of 7-8 $\mathrm{Am}^{-2}$. Biofilm produced was also of a calculable value. If the experiments are carried out under proper and appropriate conditions the Thermincola can be utilized in production of high voltage of current densities that are an important constituent of MFC [25].

\subsubsection{Microbial Fuel cells- Their role in production of current}

Activity of microbes is limited by the redox potential of anodes. The mediator, microorganisms, and a solution filled with substrate are placed in a sealed chamber to prevent oxygen entry. An electrode is placed in this chamber to act as the anode [26]. In a second chamber, another solution with an oxidizing agent and the positively charged cathode are placed. This solution is what picks up electrons at the cathode. A wire links the two electrodes and the circuit is completed by a salt bridge or proton exchange membrane. Electrons from the cell to the electrode are transported by the reduced mediator. The mediator then deposits the electrons and is oxidized [26]. From here they cross the wire to the second electrode and are taken up by the oxidizing material. This forms current and is what can be harnessed for the generation of electricity [6].

The substrate is the most crucial component of this system as it is the first thing used in the process. The best substrate found in the previous studies is glucose [27]. However, many other organic or inorganic substrates including waste water, either synthetic or non-synthetic can be used. This creates the possibility of energy production while eliminating wastewater [27]. Micro-sized MFCs can be used to convert waste into energy as well as power on-chip electronics or sensors [27]. Therefore, the potential applications of MFCs are very diverse.

\subsubsection{Microbial Fuel Cells functioning}

A bio-electrochemical device that generates electric current by using bacteria is known as Microbial Fuel Cell (MFC). MFCs are a currently a topic of intense research and interest due to their ability to produce renewable energy along with added benefits such as wastewater treatment [8]. In order to produce electric current, MFCs use bacteria as a catalyst to oxidise organic or inorganic matter [27]. In MFC electrons produced by bacteria pass through an exocellular pathway to an electrode of negative potential and flow towards an electrode of positive potential, both of these electrodes are linked through a conductive material or a resistor, as shown in Fig. 5 [28]. 


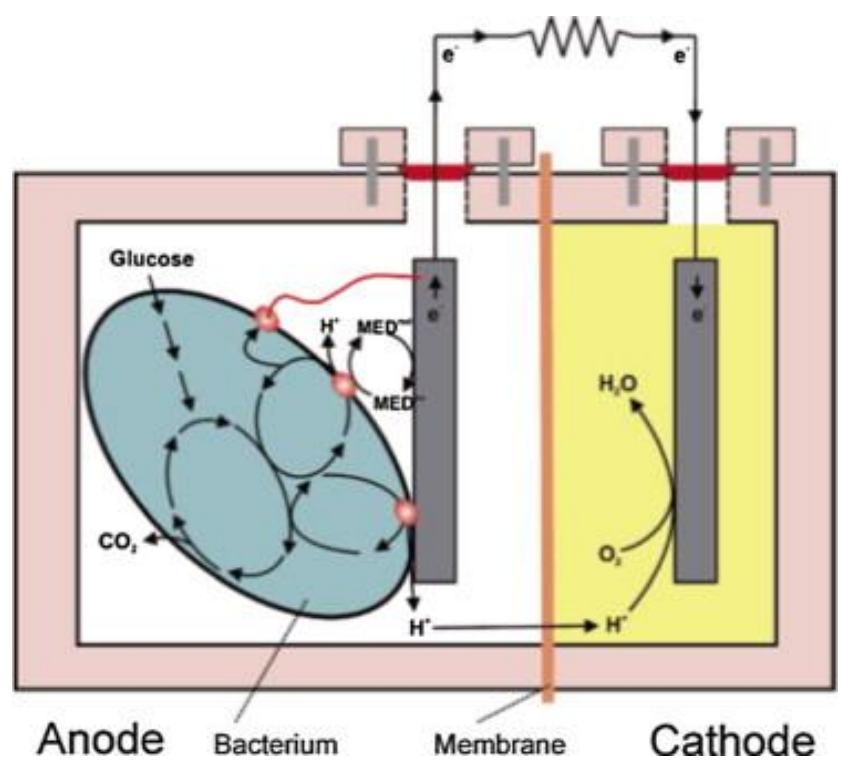

Fig. 5 An overview of a fuel cell based on the ARB (Rahimnejad et al., 2015)

\subsubsection{Extracellular transport of electrons-vital for conduction of electric current}

The anode respiring bacteria in microbial fuel cells oxidizes the substrate to produce electric current. The transfer of electrons is necessary to generate the current. The transfer of electrons is done by the anode respiring bacteria. For the purpose of transfer of electrons ARB adopts different processes. These processes includes the direct contact with the substrate via outer- membrane proteins or through diffusion or electron transport through solids by formation of bio films [29].

High current densities cannot be obtained by the mechanism of direct contact. Hurdle faced during the diffusion mechanism was that it resulted in the huge potential loss, concentration limits and moderate voltage of current was generated [30]. The only effective method for the transfer of electrons was observed to be the process of transfer of electrons from the solid surface by the formation of bio film. The results obtained showed the maximum generation of electric current and minimum loss of anode potential.

\subsubsection{Generation of electric current by Anode Respiring Bacteria}

The best method found in studies to generate electric current by ARB is mediated through the ARBs ability to transfer electrons extracellular to an anode. There are two main types of MFCs that are researched in this study. These are the mediated and mediator-free types of MFCS. It is found in studies that most microbial cells are electrochemically inactive and require a mediator such as methylene blue or humeric acid to carry and transfer the electrons generated by the bacteria. However, some micro bacteria are electrochemically active and has the ability to transfer electrons directly to the electrode without any mediator. Although, studies show the use of mediators with different combinations of micro bacterium and mixed biofilm create the potential for higher power generation and a more stable current [6]. This is because power generation is high with low loss of potential in the anode. The AFBs job is basically through the use of a substrate (ex. Glucose, waste, activated sludge) to cause the release of electrons which can be based to an anode and create and electrical current which can be utilized for energy production on a small scale [31]. This, with improved efficiency, can eventually be used on a more economical scale. In other researches, many methods of electron transfer are found that an AFB can use [32]. These include: direct contact from diffusion of soluble shuttles of electron, proteins of outer-membrane, and through extra cellular matrix of biofilm made of solid components [9]. According to (Torres et al., 2009), to achieve high current densities, having a solid conducting matrix is most effective then low anode potentials [33].

\subsubsection{Development of microbial electrolysis cell from a microbial fuel cells}

The microbial fuel cells considered as a main component of the bioelectric chemical series. Microbial fuel cells are rising due to the discovery of anode respiring bacrteria. Microbial fuel cells are responsible for the conduction of electrons [27]. The electrons are transported to the extracellular communities via different mechanisms. The transfer of electron is done by controlling the anode potential in the cell [9].

Microbial fuel cells do not require any aid or helper anode. By performing different experiments it is evident that the MFC produced by Anode Respiring Bacteria are converted to microbial electrolysis cell because of the oxygen interference from cathode. Bacterial communities of anode consists of 16s rRNA. Many cloned libraries of anode respiring bacteria dine the acetic acid decreased species to microbial electrolysis cell from the microbial fuel cells [34]. 
For this purpose the bacterial specie Geobacter sulfurreducens was used. The decrease in the number of colonies of G.sulffereducens indicated the conversion of MFC to MEC. In general terms it can be said that throughout the reaction the character of Geobacteriacae remained constant. During the experiments by Kiely et al., (2011), it was found that the overall static of G.sulffereducen reduced but there was rise in the number of G.metallireducen [35].

\section{Discussion}

There are many possible applications of MFC systems and the ARBs used in them. These include power generation, education, biosensors, bio recovery, and wastewater management; we have talked about the capabilities of MFC systems to produce energy. The method is to use chemical energy to fuel the generation of electrical energy through the utilization of anode respiring bacteria [35]. Simple MFCs are rather inexpensive, although inefficient, and make for good tools of education. They can be used to the disciplines of microbiology, geochemistry, and electrical engineering. They are able to be formed from common materials and would make for an exceptional tool for the further development of more advanced MFC systems as well as for other forms of advancement in the related fields. MFC and ARBs can also be used for biorecovery by producing energy as well as regenerating metals to reduced forms [37].

Waste water treatment is also another aspect of MFC which we have talked about throughout this literature review. Wastewater can be used as substrate to power MFC systems to not only form a stable current for the generation of electricity, but also, at the same time, to clean wastewater to make it able to be used again without the additional requirements of electricity [38].Therefore, it is obvious that the potential of MFC and ARBs is very high and their application in multiple disciplines is a very realistic approach towards advancement and education.

The biodegradable compounds can be directly converted into electricity by action of MFC. The current produced by microbes is not of a high voltage that can be used to run high projects; despite of this fact MFC still has many useful advantages. Among the advantages of MFC, some well known are, wastewater treatment, bioremediation, biofuel biosensors and other aspects. Biological oxygen demand can be calculated by calculating linear relationship between MFC and BOD [39]. The current produced via MFC is still not enough to run high power projects. Fig. 6, below describes benefits of MFCs [40].

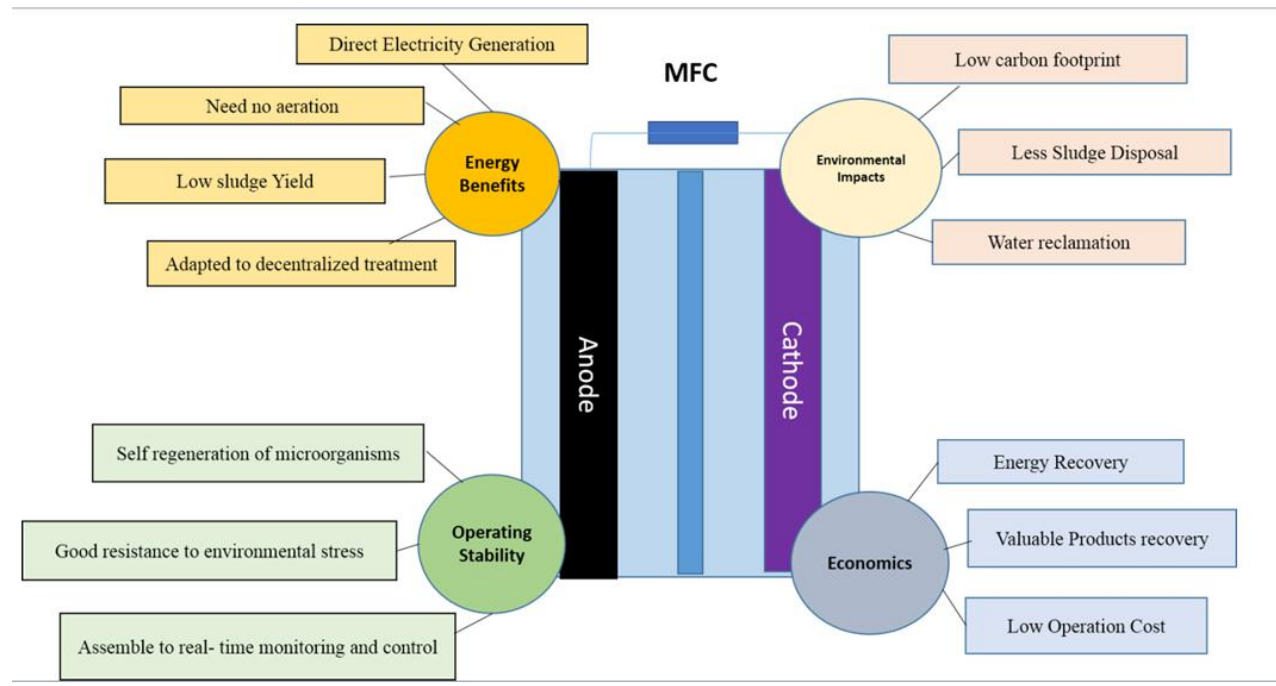

Fig. 6 Benefits of electricity production through microbial fuel cell (Source: Cameron, Kimberlynn Dawn)

Scientists are working hard in order to apply the science of microfuels and electricity produced by them in order to reduce the utilization of all the synthetic compounds that can harm the normal being. As for now the microfuels are quite expensive that is the main reason behind their unavailability. Microbiologist and other scientists are working to reduce their cost and enhance the production of biofuels using the approach of machine learning [41-45]. The enhanced production of biofuels will result in greater production of electricity. It will also help in treatment of wastewater which will eventually help in meeting the needs of water scarce regions [46]. In future, scientists aim to set low cost high production reactors that will yield in high output of current. The use of innovative technology such as machine learning will help apply these applications efficiently [47-52]. 
Table 1 Data derived through machine learning on identification of the Anode Respiring Bacteria

\begin{tabular}{|c|c|c|c|}
\hline $\begin{array}{l}\text { Best Method for anode } \\
\text { respiring bacteria anode } \\
\text { potential }\end{array}$ & $\begin{array}{l}\text {-use biofilm microbial electrolysis cell that } \\
\text { contains four graphite rods. }\end{array}$ & $\begin{array}{l}\text { the best substrate and the } \\
\text { inoculums that should be used } \\
\text { are found as acetate and waste- } \\
\text { water activated sludge, } \\
\text { respectively }\end{array}$ & ( Pierra et al., 2015) \\
\hline $\begin{array}{l}\text { Best Energy } \\
\text { Determining method }\end{array}$ & Using anode potential of ARB. & & (Torres et al., 2009) \\
\hline $\begin{array}{l}\text { Effective method for } \\
\text { electrons transfer }\end{array}$ & Solids to the surface by the formation of bio film & $\begin{array}{l}\text { Benefit: maximum generation of } \\
\text { electric current and minimum loss } \\
\text { of anode potential. }\end{array}$ & $\begin{array}{l}\text { Rabaey \& Rozendal, } \\
\text { 2010) }\end{array}$ \\
\hline $\begin{array}{l}\text { Best Bacterial Species } \\
\text { for current generation }\end{array}$ & $\begin{array}{l}\text { Thermincola are best species for production of } \\
\text { high voltage of current densities. }\end{array}$ & $\begin{array}{l}\text { Benefit: This, with improved } \\
\text { efficiency, can eventually be used } \\
\text { on a more economical scale. }\end{array}$ & $\begin{array}{l}\text { (Parameswaran et al., } \\
\text { 2013). }\end{array}$ \\
\hline $\begin{array}{l}\text { Best methods of electron } \\
\text { transfer }\end{array}$ & $\begin{array}{l}\text { diffusion of soluble shuttles of electron, through } \\
\text { proteins of outer-membrane, and through extra } \\
\text { cellular matrix of biofilm made of solid } \\
\text { components }\end{array}$ & $\begin{array}{l}\text { Reason: To achieve high current } \\
\text { densities, having a solid } \\
\text { conducting matrix is most } \\
\text { effective then low anode } \\
\text { potentials. }\end{array}$ & $\begin{array}{l}\text { (Lefebvre, } \\
\text { Kharkwal, } \quad \& \quad \mathrm{Tan}, \\
\text { 2012). }\end{array}$ \\
\hline $\begin{array}{l}\text { Best Bacterial species for } \\
\text { development of a } \\
\text { microbial electrolysis cell } \\
\text { from microbial fuel cells }\end{array}$ & $\begin{array}{l}\text { For this purpose the bacterial specie Geobacter } \\
\text { sulfurreducens is found the best. }\end{array}$ & $\begin{array}{l}\text { In general terms it can be said } \\
\text { that throughout the reaction the } \\
\text { character of Geobacteriacae } \\
\text { remained constant provides } \\
\text { maximum amount of energy. }\end{array}$ & (Kiely et al., 2011), \\
\hline $\begin{array}{l}\text { Benefits of using ARB } \\
\text { and MFCs }\end{array}$ & $\begin{array}{l}\text { Power generation, education, biosensors, bio } \\
\text { recovery, and waste management; inexpensive, } \\
\text { although inefficient, and make for good tools of } \\
\text { education, bio recovery by producing energy as } \\
\text { well as regenerating metals to reduced } \\
\text { forms. Waste water treatment is also another } \\
\text { aspect of MFC }\end{array}$ & $\begin{array}{l}\text { Biological oxygen demand can be } \\
\text { calculated by calculating linear } \\
\text { relationship between MFC and } \\
\text { BOD (ZHANG, JIANG, \& Ying, } \\
\text { 2015) }\end{array}$ & $\begin{array}{l}\text { (Du, Li, \& Gu, } \\
\text { 2007); Sonawane et } \\
\text { al., 2017; (Rittmann, } \\
\text { 2008)). }\end{array}$ \\
\hline
\end{tabular}

\section{Conclusion}

This article utilizes the effectiveness of AI to evaluate the role of Anode Respiring Bacteria in current generation via MFCs. Data was collected by using artificial intelligence techniques and ANN modeling was performed because of its capability to process huge volumes of data [53-54]. It gave a detailed description of best possible methods for the generation of electricity through microbial fuel cells. Moreover, it also described the optimum conditions for Anode Respiring Bacteria and their role in formation of MFCs and evaluated their capability for electric current production. Different factors determining the efficiency of MFCs were also discussed under data analysis section. This article has addressed the recent advancements made in this area regarding the production of low cost microbes, their availability and utilization of current produced by them. Research is being conducted on these fuel cells having the potential of renewable energy. These MFCs have been used in a number of sectors including energy sector, for wastewater treatment, as biosensors and as a source of biohydrogen. In order to decrease the market cost of biofuels, low cost reactors are set to meet the demand. Moreover, the application of MFCs as a biosensor also needs attention as this is the least explored domain of MFCs utility. Despite of more than a decade of research on MFCs, they still lag behind in terms of power generation and are unable to be used and installed at commercial levels. This shows the significance of improvement of current technologies in order to establish an efficient set up of MFCs. Our study has provided a comprehensive overview of current advancements and this will serve as a basis to further design novel research projects for manipulating microbes to get a better experimental yield of MFCs.

\section{References}

[1] Lefebvre, O., Tan, Z., Kharkwal, S., \& Ng, H. Y. Effect of increasing anodic NaCl concentration on microbial fuel cell performance. Bioresour Technol, 112, 336-340. doi: 10.1016/j.biortech.2012.02.048

[2] Torres, C. I., Krajmalnik-Brown, R., Parameswaran, P., Marcus, A. K., Wanger, G., Gorby, Y. A., \& Rittmann, B. E. Selecting anode-respiring bacteria based on anode potential: phylogenetic, electrochemical, and microscopic characterization. Environmental science \& technology; 2009, 43(24), 9519-9524.

[3] Zhou, D., Dong, S., Ki, D., \& Rittmann, B. E. Photocatalytic-induced electron transfer via anode-respiring bacteria (ARB) at an anode that intimately couples ARB and a TiO 2 photocatalyst. Chemical Engineering Journal; 2018, 338, 745-7

[4] Rabaey, K., Lissens, G., Siciliano, S. D., \& Verstraete, W. A microbial fuel cell capable of converting glucose to electricity at high rate and efficiency. Biotechnology letters; 2003, 25(18), 1531-1535.

[5] Pierra, M., Carmona-Martínez, A. A., Trably, E., Godon, J. J., \& Bernet, N. Microbial characterization of anode-respiring bacteria within biofilms developed from cultures previously enriched in dissimilatory metal-reducing bacteria. Bioresource technology; 2015, 195, 283-287. 
[6] Lee, H.-S., Torres, C. I., \& Rittmann, B. E.. Effects of substrate diffusion and anode potential on kinetic parameters for anoderespiring bacteria. Environmental science \& technology; 2009, 43(19), 7571-7577.

[7] Liu, H., \& Logan, B. E. Electricity generation using an air-cathode single chamber microbial fuel cell in the presence and absence of a proton exchange membrane. Environmental science \& technology; 2004. 38(14), 4040-4046.

[8] Heilmann, J., \& Logan, B. E. Production of electricity from proteins using a microbial fuel cell. Water Environment Research,; 2006, 78(5), 531-537.

[9] Logan, B. E. (2009). Exoelectrogenic bacteria that power microbial fuel cells. Nature Reviews Microbiology, 7(5), 375.

[10] Chen, C.-Y., Chen, T.-Y., \& Chung, Y.-C. (2013). A comparison of bioelectricity in microbial fuel cells with aerobic and anaerobic anodes. Environmental Technology, 35(3), 286-293.

[11] Flimban, S. G., Ismail, I. M., Kim, T., \& Oh, S. E. (2019). Overview of recent advancements in the microbial fuel cell from fundamentals to applications: design, major elements, and scalability. Energies, 12(17), 3390.

[12] Rabaey, K., Boon, N., Siciliano, S. D., Verhaege, M., \& Verstraete, W. Biofuel cells select for microbial consortia that selfmediate electron transfer. Applied and environmental microbiology; 2004, 70(9), 5373-5382.

[13] Munawar, H. S., Qayyum, S., Ullah, F., \& Sepasgozar, SBig Data and Its Applications in Smart Real Estate and the Disaster Management Life Cycle: A Systematic Analysis. Big Data and Cognitive Computing; 2020, 4(2).

[14] Munawar, H. S., Zhang, J., Li, H., Mo, D., \& Chang, L. Mining multispectral aerial images for automatic detection of strategic bridge locations for disaster relief missions. In Pacific-Asia Conference on Knowledge Discovery and Data Mining (pp. 189200). Springer, Cham. . (2019, April)

[15] Munawar HS, Hammad A, Ullah F, Ali TH. After the flood: A novel application of image processing and machine learning for post-flood disaster management. In Proceedings of the 2nd International Conference on Sustainable Development in Civil Engineering (ICSDC 2019), Jamshoro Pakistan 2019 Dec (pp. 5-7).

[16] Munawar HS, Awan AA, Khalid U, Munawar S, Maqsood A. Revolutionizing Telemedicine by Instilling H. 265. International Journal of Image, Graphics \& Signal Processing. 2017 May 1;9(5).

[17] Hafiz Suliman Munawar, " Applications of Leaky-wave Antennas: A Review ", International Journal of Wireless and Microwave Technologies(IJWMT), Vol.10, No.3, pp. 56-62, 2020.DOI: 10.5815/ijwmt.2020.03.05

[18] Hafiz Suliman Munawar, " An Overview of Reconfigurable Antennas for Wireless Body Area Networks and Possible Future Prospects ", International Journal of Wireless and Microwave Technologies(IJWMT), Vol.10, No.2, pp. 1-8, 2020.DOI: 10.5815/ijwmt.2020.02.01

[19] Munawar, H. S., Khalid, U., Jilani, R., \& Maqsood, A. (2017). Version Management by Time Based Approach in Modern Era. International Journal of Education and Management Engineering, 4, 13-20.

[20] Hafiz Suliman Munawar, " Reconfigurable Origami Antennas: A Review of the Existing Technology and its Future Prospects ", International Journal of Wireless and Microwave Technologies(IJWMT), Vol.10, No.4, pp. 34-38, 2020.DOI: 10.5815/ijwmt.2020.04.04

[21] Munawar, H. S., \& Maqsood, A. Isotropic Surround Suppression based Linear Target Detection using Hough Transform.

[22] Aelterman, P., Freguia, S., Keller, J., Verstraete, W., \& Rabaey, K.. The anode potential regulates bacterial activity in microbial fuel cells. Applied microbiology and biotechnology; 2008, 78(3), 409-418.

[23] Yasri, N. G., \& Nakhla, G. Electrochemical Behavior of Anode-Respiring Bacteria on Doped Carbon Electrodes. ACS Applied Materials \& Interfaces; 2016, 8(51), 35150-35162. doi: 10.1021/acsami.6b09907

[24] Mahmoud, M., Parameswaran, P., Torres, C. I., \& Rittmann, B. E. Electrochemical techniques reveal that total ammonium stress increases electron flow to anode respiration in mixed - species bacterial anode biofilms. Biotechnology and bioengineering; 2017, 114(6), 1151-1159.

[25] Parameswaran, P., Bry, T., Popat, S. C., Lusk, B. G., Rittmann, B. E., \& Torres, C. I.. Kinetic, electrochemical, and microscopic characterization of the thermophilic, anode-respiring bacterium Thermincola ferriacetica. Environmental science \& technology; 2013, 47(9), 4934-4940.

[26] Mink, J. E., \& Hussain, M. M..Sustainable design of high-performance microsized microbial fuel cell with carbon nanotube anode and air cathode. Acs ; 2013, 7(8), 6921-6927.

[27] Liu, H., Cheng, S., \& Logan, B. E.. Production of electricity from acetate or butyrate using a single-chamber microbial fuel cell. Environmental science \& technology; 2005, 39(2), 658-662.

[28] He, Z., Minteer, S. D., \& Angenent, L. T. Electricity generation from artificial wastewater using an upflow microbial fuel cell. Environmental science \& technology; 2005, 39(14), 5262-5267.

[29] Logan, B. E., Hamelers, B., Rozendal, R., Schroder, U., Keller, J., Freguia, S.,Rabaey, K. Microbial fuel cells: methodology and technology. Environ Sci Technol; 2006, 40(17), 5181-5192.

[30] Rahimnejad, M., Adhami, A., Darvari, S., Zirepour, A., \& Oh, S. E. Microbial fuel cell as new technology for bioelectricity generation: a review. Alexandria Engineering Journal; 2015, 54(3), 745-756.

[31] Torres, C. I., Kato Marcus, A., \& Rittmann, B. E.. Proton transport inside the biofilm limits electrical current generation by anode - respiring bacteria. Biotechnology and Bioengineering; 2008, 100(5), 872-881.

[32] Torres, C. I., Marcus, A. K., Lee, H.-S., Parameswaran, P., Krajmalnik-Brown, R., \& Rittmann, B. E. A kinetic perspective on extracellular electron transfer by anode-respiring bacteria. FEMS microbiology reviews; 2009, 34(1), 3-17.

[33] Park, D. H., \& Zeikus, J. G. Improved fuel cell and electrode designs for producing electricity from microbial degradation. Biotechnology and Bioengineering; 2003, 81(3), 348-355.

[34] Baudler, A., Schmidt, I., Langner, M., Greiner, A., \& Schröder, U.. Does it have to be carbon? Metal anodes in microbial fuel cells and related bioelectrochemical systems. Energy \& Environmental Science; 2015, 8(7), 2048-2055.

[35] Kiely, P. D., Cusick, R., Call, D. F., Selembo, P. A., Regan, J. M., \& Logan, B. E. Anode microbial communities produced by changing from microbial fuel cell to microbial electrolysis cell operation using two different wastewaters. Bioresource technology; 2011, 102(1), 388-394.

[36] Du, Z., Li, H., \& Gu, T.. A state of the art review on microbial fuel cells: a promising technology for wastewater treatment and bioenergy. Biotechnology advances; 2007, 25(5), 464-482. 
[37] Sonawane, J. M., Yadav, A., Ghosh, P. C., \& Adeloju, S. B. Recent advances in the development and utilization of modern anode materials for high performance microbial fuel cells. Biosensors and Bioelectronics; 2017, 90, 558-576.

[38] Rittmann, B. E. Opportunities for renewable bioenergy using microorganisms. Biotechnology and Bioengineering; 2008, $100(2), 203-212$.

[39] ZHANG, Y.-C., JIANG, Z.-H., \& Ying, L. Application of electrochemically active bacteria as anodic biocatalyst in microbial fuel cells. Chinese Journal of Analytical Chemistry; 2015, 43(1), 155-163.

[40] Cameron, Kimberlynn Dawn. Microbial Fuel Cell Possibilities on American Indian Tribal Lands. No. SAND2016-7820PE. Sandia National Lab.(SNL-NM), Albuquerque, NM (United States), 2016.

[41] Niessen, J., Schröder, U., \& Scholz, F. Exploiting complex carbohydrates for microbial electricity generation-a bacterial fuel cell operating on starch. Electrochemistry Communications; 2004, 6(9), 955-958.

[42] Munawar, H. S., Khalid, U., \& Maqsood, A. Fire detection through Image Processing; A brief overview.

[43] Munawar, H. S., Khalid, U., \& Maqsood, A. Modern day detection of Mines; Using the Vehicle Based Detection Robot.

[44] Munawar, H. S., Qayyum, S., Ullah, F., \& Sepasgozar, S. (2020). Big Data and Its Applications in Smart Real Estate and the Disaster Management Life Cycle: A Systematic Analysis. Big Data and Cognitive Computing, 4(2), 4.

[45] Munawar HS, Awan AA, Maqsood A, Khalid U. REINVENTING RADIOLOGY IN MODERN ERA.

[46] Mohammed Awad, Mohammed Zaid-Alkelani, "Prediction of Water Demand Using Artificial Neural Networks Models and Statistical Model", International Journal of Intelligent Systems and Applications(IJISA), Vol.11, No.9, pp.40-55, 2019. DOI: 10.5815/ijisa.2019.09.05.

[47] Watanabe, K. Recent developments in microbial fuel cell technologies for sustainable bioenergy. Journal of bioscience and bioengineering; 2008, 106(6), 528-536.

[48] Munawar HS, Hammad A, Ullah F, Ali TH. After the flood: A novel application of image processing and machine learning for post-flood disaster management. InProceedings of the 2nd International Conference on Sustainable Development in Civil Engineering (ICSDC 2019), Jamshoro Pakistan 2019 Dec (pp. 5-7).

[49] Munawar, H. S., Zhang, J., Li, H., Mo, D., \& Chang, L. (2019, April). Mining multispectral aerial images for automatic detection of strategic bridge locations for disaster relief missions. In Pacific-Asia Conference on Knowledge Discovery and Data Mining (pp. 189-200). Springer, Cham.

[50] Munawar, H. S. (2020). Flood Disaster Management: Risks, Technologies, and Future Directions. Machine Vision Inspection Systems: Image Processing, Concepts, Methodologies and Applications, 1, 115-146.

[51] Munawar, H. S. (2020). Image and Video Processing for Defect Detection in Key Infrastructure. Machine Vision Inspection Systems: Image Processing, Concepts, Methodologies and Applications, 1, 159-177.

[52] Rabaey, K., \& Rozendal, R. A. Microbial electrosynthesis-revisiting the electrical route for microbial production. Nature Reviews Microbiology; 2010, 8(10), 706.

[53] Baisakhi Chatterjee, Himadri Nath Saha, "Parameter Training in MANET using Artificial Neural Network", International Journal of Computer Network and Information Security(IJCNIS), Vol.11, No.9, pp.1-8, 2019.DOI: 10.5815/ijcnis.2019.09.01.

[54] Ahmed S. Mahedy, Abdelazeem A. Abdelsalam, Reham H. Mohamed, Ibrahim F. El-Nahry, "Utilizing Neural Networks for Stocks Prices Prediction in Stocks Markets", International Journal of Information Technology and Computer Science(IJITCS), Vol.12, No.3, pp.1-7, 2020. DOI: 10.5815/ijitcs.2020.03.01.

\section{Authors' Profiles}

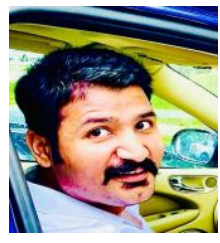

Mustafa Pasha is an independent consultant on computational modelling and simulation on medical and health related topics. He has a master's in computational sciences and engineering from NUST, Pakistan and a PhD in Applied computing from Lincoln, New Zealand. He has a dedicated set of expertise in drug design and discovery, his past work includes work on cancer cell proliferation and human cell cycle modelling and simulation. Besides his research profile, he has number of achievements in health business, procurement, and novel solutions consultations. He holds the privilege to be nominated in Canterbury Business Champion, New Zealand. His research interests include, Pharmaceutical Formulations, Intelligent Modelling and Simulation, Artificial intelligence, Machine learning, Data Analysis, Industrial Business Consultancy and regulatory affairs

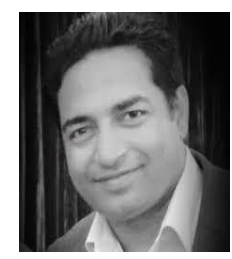

Khurram Munawar is a PhD student at the Lincoln University (New Zealand) He is a multi-disciplinary researcher with experience in Computer Visualization, machine learning, computational sciences, computational modeling and artificial intelligence, he has several international publications in various journals and conferences and has actively been working in Visualization and Artificial Intelligence domain.

How to cite this paper: Mustafa Kamal Pasha, Khurram Munawar, " Data Driven Through Machine Learning on Electricity Production by Anode Respiring Bacteria Using the Microbial Fuel Cells", International Journal of Education and Management Engineering (IJEME), Vol.11, No.3, pp. 1-10, 2021. DOI: 10.5815/ijeme.2021.03.01 